\title{
PSICOANÁLISIS Y CRUELDAD
}

\author{
PSYCHOANALYSIS AND CRUELTY
}

\author{
Felipe León-Cádiz* \\ Foro Analítico Metropolitano de Santiago \\ Santiago-Chile \\ Recibido marzo de 2020/Received March, 2020 \\ Aceptado septiembre de 2020/Accepted September, 2020
}

\begin{abstract}
RESUMEN
Este texto aborda los estudios psicoanalíticos realizados por Sigmund Freud acerca de la crueldad. La hipótesis a desarrollar plantea una teoría de la crueldad a partir del funcionamiento psíquico del sujeto, donde la realidad social pueda ser comprendida a la luz de la teoría del inconsciente. Se utiliza como punto de partida la afirmación de Freud en ¿Por qué la guerra? donde indica tres móviles para la crueldad: tendencias de orden erótico, tendencias destructivas y los ideales. Para las tendencias de orden erótico se hablará del sadismo como manifestación de la pulsión sexual. Para las tendencias destructivas se abordará la pulsión de muerte y su prolongación en la noción de pulsión de destrucción. En lo que concierne a los ideales, el superyó y el ideal del yo serán discutidos en su relación con la crueldad. Este recorrido pretende exponer la crueldad como acto individual pero indisociable de su aparición en la escena pública.
\end{abstract}

Palabras Clave: Crueldad, Sadismo, Pulsión de Muerte, Ideales, Freud.

\begin{abstract}
This text addresses the psychoanalytic studies carried out by Sigmund Freud about cruelty. The hypothesis to be developed raises a theory of cruelty based on the psychic functioning of the subject, where social reality can be understood in light of the theory of the unconscious. Freud's statement in "Why War?" is used as a starting point in which he distinguishes three motives for cruelty: erotic tendencies, destructive tendencies, and ideals. Regarding erotic tendencies, sadism will be discussed as a manifestation of sexual drive. For destructive tendencies, the death drive and its extension in terms of the drive for destruction will be addressed. Regarding ideals, the superego and the ego ideal will be discussed in relation to cruelty. This journey aims to expose cruelty as an individual act yet inseparable of its public appearance.
\end{abstract}

Key Words: Cruelty, Sadism, Death Drive, Ideals, Freud.

\section{INTRODUCCIÓN}

La crueldad, lo crudo, lo sangriento, lo incivilizado, la sangre que se derrama fuera de la ley, como una especie de canibalismo que aterroriza el corazón del vínculo social. Como expresa su etimología: "La raíz indoeuropea expresa las nociones de 'carne cruda, sangrante', 'sangre derramada". En latín cruor significa "la sangre derramada", crudus: "sangrante", crudelis: "quien se regocija en la sangre", "quien es cruel" (Cupa, 2002, p. 1073).
En Freud, la crueldad (Grausamkeit) sin ser un concepto "claro", tiene un papel repetitivo en el edificio psicoanalítico. Derrida subraya la recurrencia freudiana: "Más de una vez alude al 'placer de la agresión y la destrucción' (Die Lust an der Aggression und Destruktion), a las 'innumerables crueldades de la historia' (ungezahlte Graussamkeiten der Geschichte), a las 'atrocidades de la historia' (Greueltaten der Geschichte), a las 'crueldades de la Santa Inquisición' (Graussamkeiten der hl. Inquisition)" (Derrida, 2000, p. 14). 
Cada vez que surge la crueldad a nivel social, el sujeto experimenta la situación con el unheimliche (lo ominoso) de la extrañeza. Cuando el grupo social, la comunidad de derecho, el Estado protector, revelan su rostro obsceno, violento y cruel, actualizan a nivel individual la internalización de la ley mediante la amenaza de la pérdida del amor y del castigo, mientras que a nivel social revive a la horda original con su padre omnipotente, que somete a la horda a su deseo ilimitado. El unheimliche aparece allí con la violencia que surge de los fundamentos de las relaciones sociales y que se apropia del espacio familiar, de las instituciones que se crean precisamente para protegerse de la violencia del prójimo. Quizás la característica básica de la crueldad dentro del Estado es su ambivalencia, su Gewalt alemán profundizada por Walter Benjamin (Benjamin, 2020), intraducible al español, entendido como el lugar donde el poder y la violencia se fundan el uno al otro y que el sujeto experimenta como extraño y aniquilador, pero que es, en sí mismo, el reflejo de su propia crueldad.

La crueldad es un exceso inasimilable de la relación entre violencia y poder. Su definición, su delimitación, siempre ha sido confusa. Si bien existen discursos acerca de la violencia: tipologías jurídicas, explicaciones y escenarios psicológicos y sociológicos, estadísticas de su progresión y su retroceso, la crueldad surge como un residuo fuera de los límites en los que se entiende la violencia como expresión de la lucha entre el poder y el contrapoder (Balibar, 2005).

Pensada como una violencia autodestructiva, irracional, bárbara, aterradora, los intentos de entender la crueldad van desde su explicación como patología del sujeto, reflejo de una patología social que no logra impedir la transgresión de la norma (véase Anomia Social (Merton, 1979) o la Ética de Nicómaco (Abril, 2001)) hasta los argumentos que plantean la crueldad como un recurso práctico desde un cálculo costo-beneficio para evitar un daño mayor (véase La guerra preventiva contra el terror (Terestchenko, 2006)). La heterogeneidad de abordajes para entender la crueldad ilustra la dificultad para ubicar el lugar que ocupa en el lazo social ¿es una excepción?, ¿una perversión al interior de la comunidad?, ¿o es la regla que esta pasión humana sea de las más antiguas y de las más recurrentes?

El aporte freudiano a la comprensión del fenómeno expone la influencia pulsional que se escenifica al interior del sujeto, de la masa, de las instituciones, del Estado: la tendencia del Eros a formar una comunidad a partir de la restricción de la libertad del hombre y la disposición del Tánatos a la sumisión y la destructividad hacia el otro.

Freud, en ¿Por qué la guerra? indica tres motivos para la crueldad: "El entrelazamiento de las aspiraciones destructivas con otras, eróticas e ideales, facilita desde luego su satisfacción" (Freud, 1991, T. XXII, p. 194). Por razones explicativas, desarrollaremos estas causas por separado, pero dejando en claro que la dinámica de su acción siempre está entrelazada. Es decir, que la libido (los deseos de orden erótico) no está exenta de una pulsión de destrucción para beneficio del yo, como se da en el sadismo; que la pulsión de muerte (los deseos destructivos) nunca se manifiesta tan bien como cuando está intrínsecamente mezclado con Eros y que los ideales son una construcción para contener la hostilidad de la pulsión de muerte, pero también el origen de su malestar.

\section{SADISMO}

Freud, al definir en los Tres ensayos de teoría sexual, en 1905, que "la disposición a las perversiones es la disposición originaria y universal de la pulsión sexual de los seres humanos" (Freud, 1991, T. VII, p. 211), pone en el centro de la reflexión antropológica tanto la formación sexual infantil como la dimensión de la relación intersubjetiva del lazo social.

Los Tres ensayos de teoría sexual son, en esencia, un tratado concerniente a la libido, testimonio del gran avance conceptual de construir lo sexual a partir de la sexualidad infantil. Las características de esta tesis llevan a Freud a concebir una disposición "polimórficamente perversa" en los niños, sometida al juego de las pulsiones parciales, íntimamente vinculada a la diversidad de zonas erógenas y la libre fijación libidinal ejercida por la primacía genital posterior (Freud, 1991, T. VII).

En esta construcción conceptual de la sexualidad infantil, antes del terremoto teórico ejercido por la introducción de la pulsión de muerte, un problema para Freud fue la pregunta del sadismo infantil durante la organización pregenital. Así él escribe:

La crueldad es cosa enteramente natural en el carácter infantil; en efecto, la inhibición en virtud de la cual la pulsión de apoderamiento ${ }^{1}$ 
se detiene ante el dolor del otro, la capacidad de compadecerse, se desarrollan relativamente tarde. Es notorio que no se ha logrado todavía el análisis psicológico exhaustivo de esta pulsión. Nos es lícito suponer que la moción cruel proviene de la pulsión de apoderamiento y emerge en la vida sexual en una época en que los genitales no han asumido aún el papel que desempeñarán después (Freud, 1991, T. VII, p. 175).

La génesis del sadismo durante la primera tópica de la teoría freudiana se elabora con más precisión en el texto de 1915, Pulsión y destinos de pulsión, donde sostiene que el sadismo como agresividad hacia otro niño, no busca el sufrimiento de este último y no va acompañado de ningún placer sexual. Como explica Laplanche y Pontalis:

...se define el primer fin del sadismo como la humillación y el dominio por la violencia (Überwaltigung) del objeto. El hacer sufrir no forma parte del fin originario; el fin de producir dolor y la unión con la sexualidad aparecen en la vuelta hacia el masoquismo: el sadismo, en el sentido erógeno del término, constituye el efecto de una segunda vuelta, el del masoquismo sobre el objeto (Laplanche y Pontalis, 2004, p. 328).

El sadismo, en el sentido sexual del término, implica un nuevo retorno de la posición masoquista. Esta premisa se afirma en la obra teórica freudiana en el texto Pegan a un niño (Freud, 1991, T. XVII), el que, además de establecer las premisas de la segunda tópica, ayuda a esclarecer la aparición de las mociones eróticas en el sujeto. La fantasía de flagelación infligida inicialmente a un niño tiene una connotación sádica: "El padre golpea al niño, odiado por mín". El segundo tiempo se convierte en: "Soy golpeado por el padre", donde se manifiesta la connotación masoquista. El último tiempo termina con el enunciado: "Pegan a un niño", en donde la figura del padre es reemplazada por un anónimo o un maestro. El segundo tiempo es la construcción clave del fantasma, cuando interviene el sentimiento de culpa, inconsciente y masoquista, y es posible detectar la constitución del sujeto por intermedio del fantasma, que sirve como un vínculo entre la pulsión y el Edipo.

Vemos cómo el origen sádico del eje sadomasoquista durante la primera tópica se da en la construcción del fantasma masoquista a partir de la identificación con el otro, momento en el que Freud centra el carácter específicamente sexual del sujeto. "La sexualidad interviene en el proceso de manera correlativa a la aparición de la dimensión intersubjetiva y del fantasma" (Laplanche y Pontalis, 2004, p. 430). El fantasma como construcción del sujeto frente al enigma del deseo del Otro, es en el caso del fantasma de fustigación una escena que se repite en numerosos fantasmas de contenido fálico.

El fantasma de fustigación se invierte regularmente con un alto monto de placer que conduce a la satisfacción onanista, pero en los casos observados por Freud en "pegan a un niño", "la visión de las verdaderas escenas de fustigación es sentida como insoportable" (Freud, 1991, T. XVII, p. 120). Esta recusación neurótica de la escena sádica es la consecuencia de las inhibiciones sexuales causadas por la cultura. Freud nombra al asco, el pudor y la moral, como los diques que desvían la pulsión sexual "del uso sexual y que se dirigen a un nuevo propósito, un proceso que merece ser llamado sublimación" (Freud, 1991, T. VII, p. 113).

Tanto el fantasma como la sublimación, ambos destinos de la pulsión junto con la represión, surgen por mediación del yo, poniendo al servicio de intereses narcisistas lo que alguna vez apuntaba al objeto sexual. Como señala Freud en su primera referencia a la sublimación, las fantasías son sublimaciones, edificios protectores, embellecimientos (Freud, 1991, T. I p. 288), sin embargo, la distancia con la pulsión no es absoluta. La sublimación no da abasto a la demanda incesante de la pulsión. $\mathrm{Al}$ desexualizarla, el componente erótico no logra ligar todo el componente destructivo y agresivo asociado a la libido, el que vuelve contra el propio sujeto como castigo y autopunición. Es así como el fantasma mantiene el acto perverso fuera de la realidad, pero desde su lugar insconsciente, ejerce una fascinación ambivalente, placentera y culposa ${ }^{2}$.

Robert Stoller, en su artículo Perversión y el deseo de hacer daño indica que "la actividad es perversa si la excitación erótica depende del sentimiento del individuo de cometer un pecado" (Stoller, 1984, p. 198). Esta idea, ciertamente discutible (ya que incluye la noción del mal), nos permite introducir el lugar de la falla en la dimensión intersubjetiva del fantasma y la sexualidad.

El deseo puesto en escena en el fantasma no es el del sujeto, sino el del deseo del Otro. El fantasma es una respuesta al enigma del Che 
vuoi? ["Qué quieres"]. La pregunta original del deseo no es directamente "¿Qué quiero?", sino “¿Qué quieren los demás de mí?". Esta lógica de la intersubjetividad hace posible pasar de la fantasía perversa de Pegan a un niño al fantasma socializador de Psicología de masas y análisis del yo. En Psicología de masas, Freud muestra que el niño odiado (el primer fantasma), por medio de la identificación con el líder, se transforma en el hermano amado con el que se identifica en la masa. La transición del odio al amor se obtiene mediante la renuncia. Los hermanos se aman al mismo tiempo que ceden el reclamo a una posición de privilegio. Es la transición de los celos al sentimiento de altruismo (Freud, 1991, T. XVIII). Sin embargo, el fantasma masoquista de ser sometido por el ser querido tiene una relevancia especial en la masa y el amor. La angustia social de perder el amor del líder y de la masa sostiene la alienación en el deseo del Otro. En la masa, el sujeto renuncia a que se escuche su voz. La respuesta a la pregunta " $¿ Q u e ́$ quiere la sociedad de mí?" se dice al unísono, pronunciado en un discurso compartido.

Cuando observamos que la conciencia de culpa se diluye dentro de la masa y que el sujeto realiza actos crueles e inmorales que no hubiera podido realizar cotidianamente, podemos reconocer el poder que tiene la masa para canalizar las pulsiones eróticas hacia lo que llamamos "el control de las pulsiones", donde la crueldad se ejerce en nombre de una especie de ideal de civilización, donde la figura que está excluida de la comunidad por el poder soberano se convierte en objeto de humillación, sufrimiento, martirio y muerte. Esta "psicosis de masa" es un hecho que la historia atestigua con recurrencia.

\section{LA PULSIÓN DE DESTRUCCIÓN}

La agresividad es una presión constante en el sujeto. Por un lado, apoya la autoconservación de la persona al ser el motor de la actividad, en términos hegelianos, de la lucha en el transcurso de la vida, entre el yo y el otro. Hay algunas elaboraciones freudianas, principalmente en los Tres ensayos de teoría sexual, que enfatizan el carácter primario de la agresión, asociándola con la apropiación del objeto por la musculatura y la mano. Winnicot adopta esta propiedad presexual de la agresividad para teorizar una cualidad originaria de la agresividad, una especie de tensión interna que derrama una pulsión destructiva afuera para mantener la integridad narcisista (Winnicott, 2020). Jean Bergeret lleva este factor de agresividad originario al extremo y elabora el concepto de "violencia fundamental", que homologa con un instinto de tipo animal y que estaría en la base del modo arcaico de funcionamiento mental, que se considera clásicamente como aquel que domina los procesos primarios.

La apropiación teórica de las pulsiones freudianas de autoconservación como pulsiones asexuales es incluida en Bergeret como instintos, en que los humanos y los animales se homologarían sobre la base de una causalidad biológica de violencia fundamental (Bergeret, 2000, pp. 302-310). Esta interpretación es producida por la incomprensión del devenir de la teoría de las pulsiones dentro de la obra freudiana.

La pulsión de autoconservación en la primera tópica designa todas las necesidades corporales que especificamos para la preservación de la vida del individuo, siendo el hambre su ejemplo privilegiado. La relación entre la pulsión sexual y esta necesidad corporal es opuesta: "De particularísimo valor para nuestro ensayo explicativo", escribe Freud:

[...] es la inequívoca oposición entre las pulsiones que sirven a la sexualidad, la ganancia de placer sexual, y aquellas otras que tienen por meta la autoconservación del individuo, las pulsiones yoicas. Siguiendo las palabras del poeta, podemos clasificar como «hambre» o como «amor» a todas las pulsiones orgánicas de acción eficaz dentro de nuestra alma (Freud, 1991, T. XI, pp. 211-212).

Pero el antagonismo entre el "hambre" y el "amor" fue construido originalmente por el apuntalamiento, donde las pulsiones de autoconservación indican a la sexualidad el camino hacia el objeto, para después disociarse y surgir un placer erótico irreducible al obtenido por la mera satisfacción de la necesidad.

Las sucesivas reformas llevadas a cabo por Freud en la teoría de las pulsiones tienen como resultado el cambio en la visión respecto de las funciones de autoconservación. Este cambio reclasifica la coincidencia entre la pulsión de autoconservación y la pulsión del yo. A partir de la teoría del narcisismo la pulsión de autoconservación es separada de la pulsión del yo, dentro de estas son incluidas las pulsiones sexuales, subdivididas entre la libido de objeto y la libido del yo. Después de 1920, con 
la introducción de la pulsión de muerte, Freud vio en la conservación del individuo un caso especial de la manifestación de la pulsión de vida. En el Esquema de psicoanálisis, aclaró esta posición:

Tras larga vacilación y oscilación, nos hemos resuelto a aceptar solo dos pulsiones básicas: Eros y pulsión de destrucción. (La oposición entre pulsión de conservación de sí mismo y de conservación de la especie, así como la otra entre amor yoico y amor de objeto, se sitúan en el interior del Eros) (Freud, 1991, T. XXIII, p. 146).

Mediante las diferentes posiciones que toma la autoconservación en el aparato psíquico, podemos ver implícitamente una reticencia de Freud a usar el concepto de Pulsión (Trieb) ligado a la conservación del individuo. Cuando Freud se refiere a la pulsión en general, tiende a referirse a la pulsión sexual, por ejemplo, respecto de la variabilidad del fin y la contingencia del objeto. Al contrario, para las "pulsiones" de autoconservación, las vías de acceso son definidas y los objetos determinados desde el principio. Esta es la razón por la que Freud ha utilizado numerosas veces el término necesidad (Bedürfnis) para designar la pulsión de autoconservación.

La precisión anterior es importante en el uso del término agresividad en el corpus freudiano. Antes de 1920, Freud utiliza el concepto de pulsión de agresión para refutar el texto de 1908 de Adler La pulsión de agresión en la vida y en la neurosis, donde el autor postula una primacía de la agresividad que incluye la sexualidad. La respuesta viene en Análisis de la fobia de un niño de cinco años: "No puedo decidirme a admitir una pulsión particular de agresión junto a las pulsiones sexuales y de autoconservación, con que estamos familiarizados, y en un mismo plano con ellas" (Freud, 1991, T. X p. 112).

Podemos notar una resistencia en Freud para dar una salida biológica o no sexual de la agresividad dentro de su teoría. Es como si, en su intento de delimitar este espacio de la función corporal, la pulsión de autoconservación fuera el último espacio para instalar la pulsión fuera de la pulsión sexual. Esta historia teórica continúa en el texto de 1915 Pulsión y destino de pulsiones, cuando habla del pasaje del amor al odio o los orígenes del sadismo que tratamos en la parte anterior. El odio no deriva de las pulsiones sexuales, como es el caso del amor, sino que se origina en las pulsiones de autoconservación, más precisamente en "la lucha del yo para mantenerse y afirmarse" (Freud, 1991, T. XIV, p. 132). El odio surge en este componente no libidinal del yo que se opone fundamentalmente a las pulsiones sexuales.

Si el viaje del concepto de agresión terminara aquí, habría varios elementos de apoyo para una teoría biológica de la agresión. La agresividad sería el soporte de la actividad, de la búsqueda del objeto de satisfacción por medio de la apropiación "violenta" del objeto, sería un componente de la necesidad de autoconservación, una tensión del cuerpo que homologaría al sujeto psicoanalítico a toda una serie de teorías del conductismo, la sociología, la etología, la etnología y la neurociencia. Pero es desde la concepción de la pulsión de muerte que la agresividad en el psicoanálisis toma su lugar como un elemento estructural de la teoría de las pulsiones, como si la negación de su existencia fuera el producto de la expectativa de un terreno sólido donde situarla. Freud explica esta situación de la siguiente manera: "¿Por qué nosotros mismos tardamos tanto antes de decidirnos a reconocer una pulsión de agresión, por qué vacilamos en utilizar para la teoría unos hechos que eran manifiestos y notorios para todo el mundo?" (Freud, 1991, T. XXII, p. 96).

El texto fundamental para entender la destructividad en el sujeto y la cultura es Más allá del principio del placer donde Freud nos muestra por primera vez la lucha entre Eros y Thanatos, entre la pulsión de vida que tiene como objetivo mantener la sustancia viva y reunirla en unidades cada vez más grandes y la pulsión de muerte, cuyo objetivo es disolver estas unidades y llevarlas de regreso al estado inorgánico de su dispersión, es decir, destruirlas. La pulsión de muerte designa la compulsión de repetición; el principio del nirvana y la reducción de las tensiones a cero; y la tendencia a la destrucción y la destructividad (Freud, 1991, T. XVIII). Estas características de la pulsión de muerte siempre actúan de manera silenciosa y Freud subraya la dificultad de reconocer clínicamente sus derivados:

Hallar un representante del Eros no puede provocarnos perplejidad alguna; en cambio, nos contenta mucho que podamos pesquisar en la pulsión de destrucción, a la que el odio marca el camino, un subrogado de la pulsión 
de muerte, tan difícil de asir (Freud, 1991, T. XIX, p. 43).

El problema de cómo la pulsión de muerte se hace escuchar en el mundo nos lleva a comprender la unión indisoluble entre Eros y Thanatos. El rol de Eros es liberar al organismo de la acción destructiva de Thanatos, y tiene éxito, principalmente, mediante la fusión con él. La consecuencia principal de esta fusión es que no hay libido que no sea trabajada por la pulsión de muerte. Como señala Crépon y De Launay:

Si las manifestaciones del Eros son tan tumultuosas, como dice Freud, si podemos ver que están vinculadas, en cualquier cultura, a la imagen del fuego, del consumo y, a veces, a la de una autodestrucción es que no existe una relación "amorosa" que no proceda de una composición con la pulsión de muerte, es decir, con la hostilidad y la agresión que cada uno lleva consigo (Crépon y De Launay, 2010, p. 61).

Sí, como indicamos antes, el pasaje del amor al odio en Freud en Pulsión y destino de pulsiones tiene su origen en los impulsos de autoconservación, en Malestar en la cultura él manifiesta la destructividad como la sumisión de una parte de la pulsión de muerte por el Eros:

[...] la idea de que una parte de la pulsión se dirigía al mundo exterior, y entonces salía a la luz como pulsión a agredir y destruir. Así la pulsión sería compelida a ponerse al servicio del Eros, en la medida en que el ser vivo aniquilaba a un otro, animado o inanimado, y no a su sí-mismo propio (Freud, 1991, T. XXI, p. 115).

La pulsión de destrucción ${ }^{3}$ en estos términos tendría como fin una "sublimación" de la pulsión de muerte, una salida por medio de la actividad para expulsar del yo una parte de esta misma bajo la máscara del sadismo o un vínculo entre la destrucción dirigida hacia sí mismo y la sexualidad, como es el caso del masoquismo.

Una segunda consecuencia del trabajo pulsional del Eros y Thanatos se proyecta en la obra y el problema de la civilización. Freud muestra que, en el corazón del proceso civilizatorio, existe una tendencia innata a la destructividad, que ningún mandato religioso, moral o ideológico puede disimular. La radicalidad de la crueldad en la relación entre el sujeto y el prójimo es descrita sin ambigüedades:

En consecuencia, el prójimo no es solamente un posible auxiliar y objeto sexual, sino una tentación para satisfacer en él la agresión, explotar su fuerza de trabajo sin resarcirlo, usarlo sexualmente sin su consentimiento, desposeerlo de su patrimonio, humillarlo, infligirle dolores, martirizarlo y asesinarlo. «Homo homini lupus»: ¿quién, en vista de las experiencias de la vida y de la historia, osaría poner en entredicho tal apotegma? (Freud, 1991, T. XXI, p. 108).

Ciertamente, la pulsión de dominio o la agresividad de los Tres ensayos de teoría sexual no pueden dar una explicación para el "mal" que existe, en mayor o menor medida, de acuerdo con las composiciones de la alquimia pulsional, en todos los campos del comportamiento humano. Nunca Freud había estado más cerca de Nietzsche y su elogio de la crueldad:

\begin{abstract}
Ver sufrir sienta bien, hacer sufrir todavía mejor: esta es una afirmación dura, un viejo y poderoso principio fundamental humanodemasiado humano, que por lo demás, puede que también los monos suscribirían; no en vano se cuenta que en la ideación de rebuscadas crueldades ya anuncian profusamente al hombre y, por así decir, lo "preludian". Sin crueldad no hay fiesta: así lo enseña la más vieja y larga historia del hombre, ¡y también en el castigo hay tanto de festivo! (Nietzsche, 1990, p. 118).
\end{abstract}

A pesar de la semejanza de las fuerzas destructivas que para Freud y Nietzsche animan la pasión humana, algo que no hemos dejado de enfatizar en este trabajo es que la pulsión de muerte nunca actúa sola. La civilización por medio de la pulsión de vida trata de organizar sus elementos en partes más complejas, moviliza métodos que buscan "el amor del prójimo": mediante identificaciones, de relaciones de amor inhibidas en cuanto a la meta, o del monopolio de la violencia por parte de los Estados, se intenta limitar la transgresión renunciando a la satisfacción de la agresión. Sin embargo, esta estrategia de la civilización siempre tiene un revés obsceno. La agresividad nunca se suprime, sino que se dirige contra un otro, un 
excluido de la comunidad que el poder soberano designa como objeto de la hostilidad. Este mecanismo de control de las pulsiones en nombre de un ideal de civilización sirve para fortalecer la cohesión grupal por medio de la hostilidad permanente, una guerra generalizada contra una víctima emisaria. De la misma manera que en Tótem y tabú (Freud, 1991, T. XIII), el asesinato del padre funda el vínculo social, la víctima emisaria produce la solidificación de la masa.

En la siguiente parte, profundizaremos en este principio de identificación masiva gracias a un ideal. Por el momento, queremos subrayar la forma de entrada en escena de la pulsión de destrucción dentro del aparato psíquico. Como muestra la teoría psicoanalítica, el objetivo principal del sadismo no es el sufrimiento del otro, "sino la humillación y el dominio por la violencia (Überwaltigung) del objeto" (Laplanche y Pontalis, 2004, p. 328). Esta pulsión, subrogada de la pulsión de muerte sin carga erótica, es el sustrato de la estructuración narcisista del yo y "su satisfacción se enlaza con un goce narcisista extraordinariamente elevado, en la medida en que enseña al yo el cumplimiento de sus antiguos deseos de omnipotencia" (Freud, 1991, T. XXI, p. 117). La pulsión de destruir está en la base arcaica del deseo infantil de negar lo real de los demás o más exactamente lo real como otro, es el triunfo sadiano sobre "la piel del imbécil" a quien no puede dejar de destruir, incluso si no obtiene ningún placer erótico de ello. Lacan en La ética del psicoanálisis ve en esta función fundamental de la pulsión de destrucción la voluntad de destruir, la voluntad de comenzar de nuevo; voluntad de comenzar a partir de la nada. Es el más allá de la cadena significante, es el antes de la formación del yo en relación con el otro, de la formación narcisista especular, es el retorno a la Cosa (das Ding), "aquello que de lo real primordial diremos nosotros sacamos del significante" (Lacan, 1986, p. 142); es en el goce del ser que aparece la pulsión de destrucción.

\section{LOS IDEALES}

A primera vista, parece extraño relacionar la crueldad con los ideales, especialmente si pensamos en el lugar ocupado por el ideal como un signo de cultura (Kultur): "sus representaciones acerca de una perfección posible del individuo, del pueblo, de la humanidad toda, y los requerimientos que se erigen sobre la base de tales representaciones" (Freud, 1991, T. XXI, p. 93). Es como si el ideal, en su aspiración de ser la estrella que guiaría las acciones humanas hacia el "bien", paradójicamente sea también la coartada para la explotación del otro. Para comprender los caminos que atraviesa el ideal al interior del lazo social, comenzaremos explicando su rol en los paisajes del inconsciente.

Ciertamente, el ideal ve la luz dentro de la metapsicología freudiana profundamente vinculado a la constitución de la represión. El yo, en su proceso de inscripción dentro de la cultura, que se realiza principalmente debido a las críticas que los padres ejercen en el niño, lleva a cabo un trabajo de autoevaluación y censura que funda la represión de las mociones incompatibles con esta evaluación. El Ideal del yo sirve como referencia para la formación del yo ideal, que sostiene el narcisismo perdido del yo real. Este yo real no debe entenderse como una perfección narcisista opuesta al trabajo de idealización porque él es ya un ideal, una ilusión de grandeza que el sujeto quiere reconquistar bajo la nueva forma del yo ideal, ya que el hombre "se muestra incapaz de renunciar a la satisfacción de que gozó una vez" (Freud, 1991, T. XIV, p. 91).

En la segunda tópica, específicamente en el texto El yo y el ello, el superyó aparece como una estructura asociada con el Ideal del yo. En esta obra, parecería que los dos podrían ser considerados como conceptos homologables, o más bien una sola instancia que combina las funciones de prohibición y el ideal (Freud, 1991, T. XIX). Sin embargo, esta lectura se reelabora en el texto Nuevas lecciones de introducción al psicoanálisis, donde aparece la noción de "conciencia moral" (Gewissen), la que tiene como función el condicionamiento sin cesar del yo actual al ideal. Esta función es integrada en la estructura del superyó, que está compuesta además por la autoobservación y la función del ideal. El Ideal del yo pierde su lugar de instancia del aparato psíquico y encuentra su espacio como función del superyó. Como precisa Laplanche y Pontalis:

La distinción entre estas dos últimas funciones queda especialmente ilustrada en las diferencias que Freud intenta establecer entre sentimiento de culpabilidad y sentimiento de inferioridad. Estos dos sentimientos son el resultado de una tensión entre el yo y el superyó, pero el primero guarda relación con la conciencia moral, y el segundo con el Ideal del yo, en tanto que es amado más que temido (Laplanche y Pontalis, 2004, p. 181). 
En relación con nuestra investigación respecto de la crueldad, podemos ver ciertos elementos implícitos en el funcionamiento del Ideal del yo que nos permiten comprender la constitución individual del mismo.

Como se subraya en el texto de Laplache y Pontalis (2004, pp. 180-182), el trabajo del superyó y el ideal del yo divergen hacia diferentes formas en relación con la crueldad. En el superyó, la función de la conciencia moral está directamente relacionada con el sentimiento de culpa. El superyó es tanto el resultado como el instrumento de un retorno de la agresión, de la hostilidad, y por tanto de la pulsión de muerte contra el yo. En el origen de esta verdadera crueldad hacia uno mismo, uno encuentra dos circunstancias: la primera es la angustia frente a la pérdida del amor del otro, lo que estimula la renuncia pulsional y la represión. En este punto, la autoridad permanece externa y la conciencia del mal está relacionada con el miedo a ser descubierto. Aquí el castigo toma la forma de la privación del amor. La segunda circunstancia, que también es un segundo momento, es cuando la autoridad se internaliza mediante el establecimiento del superyó. Este heredero de la autoridad paterna utiliza la función de la conciencia moral para ejercer el trabajo de censor sobre el yo. Es la conciencia la que hace que el arrepentimiento sea experimentado por los actos, pero también por los pensamientos mediante el reproche, una máquina de goce que ataca al sujeto más allá del principio del placer.

Desde este trabajo de internalización de la conciencia moral, queremos enfatizar un aspecto del narcisismo que permanece presente como sobreviviente del proceso de represión. Como indicamos en los orígenes del sadismo, el primer objetivo de este es el dominio del objeto, acción que está en la base de la estructuración narcisista del yo. La vieja elección del objeto narcisista es el producto de la idealización del yo-real como un yo omnipotente. El yo del narcisismo primario ya es parte del proceso de idealización antes de la idealización del Ideal del yo. Con la aparición del superyó, el Ideal del yo debe abandonar sus componentes de destructividad y violencia narcisista y fijarse a la identificación paterna, primer paso en la constitución del superyó. Pero es un trabajo incompleto. Hay un excedente, un plus-de-goce que no se puede asimilar. La primera causa es la resistencia al abandono por parte del yo de aquel goce narcisista de sus antiguos deseos de omnipotencia. La segunda causa es, por así decirlo, económica; después de la sublimación, la pulsión de vida no tendría la fuerza para unir la totalidad de fuerzas destructivas, por lo que "estas se liberan como inclinación de agresión y destrucción" (Freud, 1991, T. XIX, p. 55).

Esta última idea es misteriosa. Liberarse. La causalidad en el psicoanálisis nos muestra que esta libertad siempre está sujeta al juego entre la pulsión de vida y la pulsión de muerte. La tendencia a la agresión y la destrucción, como hemos visto en el sadismo, se pone al servicio del Eros en lugar de destruirse a sí mismo, aniquila a otro. Ahora bien, esta válvula de seguridad que proyecta fuera la pulsión de muerte también está determinada por el trabajo de la idealización. En la perversión, hay un trabajo de idealización sobre la misma pulsión $\mathrm{o}$, dicho en lenguaje narcisista, sobre el objeto de la pulsión.

El pervertido es por excelencia el idealista; de hecho, somete la satisfacción a requisitos estrictos, incluso draconianos [...] Este destino idealizante de la pulsión exhibido por el pervertido denuncia la oposición de una sexualidad real o bruta o corporal y una psique externa: es en el Trieb que trabaja la psique, y es por eso que la idealización sería uno de los efectos mayores (Assoun, 1983, p. 105).

El neurótico, este hombre insatisfecho por el malestar de estar sujeto a la ley, ve en el pervertido la aspiración a liberarse del mandato del ideal, como si fuera posible romper las cadenas que lo unen a este doloroso juicio de la conciencia moral. Los celos neuróticos, que imaginan un pervertido feliz, satisfecho por su relación directa con el objeto, caen ante la "realidad" idealizante de la fantasía sádica, sometida a una escena perpetuamente inaccesible.

Así, como el inconsciente es siempre colectivo, el ideal es intrínsecamente social, esencialmente un "ideal común" (Gemeinsame Ideal). Podemos ver cómo el ideal del yo pasa del plano inconsciente al plano social por medio de la identificación mutua de los otros integrantes de la masa. Este proceso de identificación se lleva a cabo mediante lazos libidinales entre miembros de la masa que permiten la restricción del narcisismo. Pero esta identificación es primariamente una identificación con el jefe, donde los miembros de la masa colocan el mismo objeto en lugar de sus "ideales", un objeto que 
es tratado como el Ideal del yo. Este objeto es el líder. Él es tocado por la idealización del colectivo, que posteriormente permite la identificación entre unos y otros.

La confluencia de las identificaciones que el sujeto realiza en el plano social forma la construcción social del ideal del yo. La Kultur, como posible perfección de una sociedad, aparece como el derivado de la construcción colectiva del ideal del yo. En este sentido, los ideales son el espejo donde la Kultur se refleja ante las acciones más elevadas y deseables del grupo cultural, llamado el "ideal cultural" (Kulturideal).

Freud no se reserva ninguna ingenuidad con respecto a la dominación de la hostilidad por la existencia del ideal cultural:

Freud subraya que la Kultur sigue determinada por la división de la explotación, mientras que al exterior los ideales culturales se convierten en una causa de discordia y enemistad entre diferentes grupos culturales y entre naciones, ya que establece el derecho a despreciar al "otro" (Assoun, 1983, p. 112).

El ideal cultural indudablemente sostiene la identificación, pero al mismo tiempo conduce a la destructividad hacia la figura excluida de la comunidad. Es la violencia que satisface el ideal. Pero $i$ es esto un anti-ideal, una "falsa conciencia" que produce como resultado una situación social que ignora su relación con la realidad? Esta pregunta coloca en el centro de la investigación sobre el ideal el dominio de la axiología del ideal, es decir, el valor de una ética del ideal. Es en este camino que el ideal se alinea con la ideología como un discurso que da una imagen de un mundo distorsionado; en lenguaje freudiano, una ilusión.

Para Freud, la ilusión es un tipo de creencia:

[...] tal que en su motivación domina una realización del deseo (Wunscherfüllung), sin tener en cuenta su relación con la realidad, de modo que la ilusión renuncia a sus confirmaciones (Beglaubigungen) [...] La ilusión puede permanecer indiferente a la realidad, en la que no tiene que fundarse (Assoun, 1983, p. 112).

En este sentido y como Freud destacó con empeño; la religión es la ideología por excelencia y el trabajo del psicoanálisis es el ejercicio de la desilusión, mostrando los fundamentos ocultos de los discursos y la pretendida racionalidad en la que se basan.

Cuando Freud utiliza a la Iglesia y el Ejército, en Psicología de masas y análisis del yo, como los principales ejemplos de masas artificiales, se centra en la pérdida de libertad en la que se somete a los sujetos que entran en estas dos instituciones. En general, dice: "no se pregunta al individuo si quiere ingresar en una masa de esa índole, ni se lo deja librado a su arbitrio y el intento de separación suele estorbarse o penarse rigurosamente, o se lo sujeta a condiciones muy determinadas" (Freud, 1991, T. XVIII, p. 89).

La soberanía del sujeto pone en juego la relación a la masa, de la misma manera que está condicionada en su relación con la ideología, razón por la que la ideología es siempre un discurso de poder, donde las relaciones entre los sujetos dentro de la comunidad, a nivel ideológico, ocultan la realidad de la explotación entre ellos, o a nivel nacional, justifica el desprecio y el deseo de aniquilación en la guerra.

Cuestionar axiológicamente la ética del ideal cultural es confrontar las ilusiones ideológicas con la realidad de la crueldad que no puede ser absorbida por el discurso. La ideología como un "fantasma" de una sociedad "idealizada" opaca al horror en el que se basa su propia condición violenta.

\section{CONCLUSIONES}

Existe una homología entre la instauración de la ley a nivel social y a nivel del inconsciente: ley social y ley de prohibición del incesto que el padre encarna como agente de la castración. Si el padre representa lo prohibido, al mismo tiempo él autoriza, abre al deseo la vía de la realidad. Porque si la castración es la pérdida del goce que introduce al sujeto en el lazo social, esta pérdida del goce está en el origen del deseo.

Partimos de la violencia de la ley y esta nos lleva a la paradoja de la violencia legítima, ya que es necesario fundar el lazo social y regular el goce, ya sea a nivel colectivo o individual. Sin duda, esta paradoja nos muestra que hay una imposibilidad allí: la imposibilidad de basar la legitimidad de la ley en algo diferente a la violencia.

Freud reconoce esta necesidad de violencia tanto a nivel individual como social. Como señala en Malestar en la cultura (Freud, 1991, T. XXI) 
la pulsión de muerte vehiculizada por el Eros se manifiesta como una pulsión agresiva y destructiva para, en lugar de destruirse a sí misma, destruya a otro. Hay entonces una violencia fundamental que oscila de la autodestrucción a la heterodestrucción. Pero esta violencia es constantemente reelaborada por el proceso de civilización, es decir, por el discurso en tanto que estructura del lazo social. En ¿Por qué la guerra? (Freud, 1991, T. XXII), considera que, si la violencia disminuye entre los individuos, es porque es confiscada por el grupo (la horda, el clan, la tribu) y luego por el Estado. Pero el fracaso de los organismos internacionales a fundar las relaciones en el derecho muestra que la ley sigue siendo fundamentalmente la ley del más fuerte. El derecho no elimina la violencia, sino que la deriva.

Respecto de este trabajo de la pulsión de muerte, Lacan, en su seminario "El sinthoma", declaró: "la pulsión de muerte es lo Real en tanto que no puede ser pensado más que como imposible, es decir, que cada vez que él muestra la punta de su nariz, es impensable" (Lacan, 2005, p. 125).

Esta imagen de lo impensable surge recurrentemente en referencia a la crueldad en el lazo social. Bion lo llama el terror sin nombre; Kaes habla del orden del vacío. Es la zona que contendría el caos y la perversión que nos permitiría albergar lo impensable. Sin embargo, Badiou contradice con lucidez esta idea, tomando la Shoah como ejemplo: "Cuando decimos, ligeramente, que lo que hicieron los nazis (el exterminio) es del orden de lo impensable, o de lo intratable, olvidamos un punto crucial, que es que los nazis lo pensaron y lo trataron, con el mayor cuidado, la mayor determinación" (Badiou, 2005, p. 14).

Lo que el conocimiento psicoanalítico nos aporta en la comprensión del lazo social es la irreductibilidad de la política a un ejercicio de poder o un proceso ético que busca el beneficio de la comunidad. En la política, así como en la cultura, la influencia pulsional es un motor que pone en escena la tendencia de Eros a formar una comunidad a partir de la restricción de la libertad del individuo y la disposición de Thanatos a la sumisión y la destructividad hacia el otro. El trabajo de la cultura no comienza en la subyugación al poder de un individuo, al poder del "más fuerte", sino en la capacidad de una comunidad para generar "un derecho (Recht) al que todos -al menos todos los capaces de vida comunitaria- hayan contribuido con el sacrificio de sus pulsiones y en el cual nadie -con la excepción ya mencionada- pueda resultar víctima de la violencia bruta (Gewalt)" (Freud, 1991, T. XXI, p. 94).

En el corazón de la política está el ideal como sostén de la ambivalencia de la pulsión, que es la dialéctica del amor y el odio de todo lazo social. En este sentido, la justicia que Freud señala cómo el producto de una evolución desde el poder del más fuerte hacia la comunidad de derecho no está lejos de las fluctuaciones que van desde el derecho a la violencia bruta, y estos dos términos no son oponibles, sino que se reencuentran en la base del lazo social sin ser complementarios.

De esta dialéctica de la Recht-Gewalt, podríamos pensar que la crueldad pertenece más al orden de la Gewalt como una violencia fundamental del vínculo social, pero es importante aclarar que la violencia no es crueldad. La crueldad es un exceso, pero siempre es un exceso porque hay una ley que debe ser transgredida. En este sentido, la crueldad es parte del Recht como un derivado de la violencia legítima que valida la crueldad hacia los excluidos de la comunidad. Por eso la crueldad es inseparable del ideal. El ideal sostiene la crueldad como un elemento permitido del poder.

En ningún caso la crueldad es el objetivo deseado por el ideal. El ideal existe en relación con el poder y se constituye como el soporte imaginario que debe demoler toda resistencia a su materialización. La violencia es el vehículo para su acción. Pero el poder no solo es violento, poderoso, brutal sino también sádico, feroz y cruel. 


\section{REFERENCIAS}

Abril, P. (2001). La ética de Aristóteles. Albacete, España: Ed. Libros en la Red.

Assoun, P.L. (1983). Freud aux prises avec l'idéal [Freud luchando con el ideal]. Nouvelle revue de psychanalyse, $\mathrm{N}^{\circ} 27$, pp. 105 y 112.

Badiou, A. (2005). El siglo [Le siècle]. París, Francia: Ed. Seuil, p. 14.

Balibar, E. (2005). Violence: idealité et cruauté [Violencia: idealidad y crueldad]. París, Francia: Ed. Odile Jacob.

Benjamin, W. (2020). Para una crítica de la violencia [Archivo PDF] https://www.philosophia.cl/biblioteca/Benjamin/violencia. pdf

Bergeret, J. (2000). Violencia fundamental. Psicoanálisis APdeBA, Vol. XXII - № 2, Buenos Aires, Argentina: Asociación Psicoanalítica de Buenos Aires, pp. 302-307 https://www.apdeba. org/wp-content/uploads/022000bergeret.pdf

Crépon, M. y De Launay, M. (2010). Anthropologie de la guerre [Antropología de la guerra]. París, Francia: Ed. Fayard, p. 61.

Cupa, D. (2002). La pulsion de cruauté [La pulsión de crueldad]. Revue française de Psychanalyse, No 4, p. 1073.

Derrida, J. (2000). États d'âme de la psychanalyse [Estados de ánimo del psicoanálisis]. París, Francia: Ed. Galilée, p. 14.

Freud, S. (1991). Análisis de la fobia de un niño de cinco años. Obras completas, Tomo X. Buenos Aires, Argentina: Ed. Amorrortu, p. 112.

Freud, S. (1991). El yo y el ello. Obras completas, Tomo XIX. Buenos Aires, Argentina: Ed. Amorrortu, pp. 43-55.

Freud, S. (1991). Esquema de psicoanálisis. Obras completas, Tomo XXIII. Buenos Aires, Argentina: Ed. Amorrortu, p. 146.

Freud, S. (1991). Carta 61 (2 de mayo de 1897). Obras completas, Tomo I. Buenos Aires, Argentina: Ed. Amorrortu, p. 288.

Freud, S. (1991). Introducción al narcisismo. Obras completas, Tomo XIV. Buenos Aires, Argentina: Ed. Amorrortu, p. 91.

Freud, S. (1911). La perturbación psicógena de la visión según el psicoanálisis. Obras completas, Tomo XI. Buenos Aires, Argentina: Ed. Amorrortu, pp. 211-212.

Freud, S.. (1991). Malestar en la cultura. Obras completas, Tomo XXI. Buenos Aires, Argentina: Ed. Amorrortu, pp. 93-94, 115-117.
Freud, S. (1991). Más allá del principio del placer. Obras completas, Tomo XVIII. Buenos Aires, Argentina: Ed. Amorrortu.

Freud, S. (1991). Nuevas conferencias de introducción al psicoanálisis. Obras completas, Tomo XXII. Buenos Aires, Argentina: Ed. Amorrortu, p. 96.

Freud, S. (1991). Pegan a un niño. Obras completas, Tomo XVII Buenos Aires, Argentina: Ed. Amorrortu, p. 120.

Freud, S. (1991). ¿Por qué la guerra? Obras completas, Tomo XXII. Buenos Aires, Argentina: Ed. Amorrortu, p. 194.

Freud, S. (1991). Psicología de masas y análisis del yo. Obras completas, Tomo XVIII. Buenos Aires, Argentina: Ed. Amorrortu, p. 89.

Freud, S. (1991). Pulsión y destino de pulsiones. Obras Completas, Tomo XIV. Buenos Aires, Argentina: Ed. Amorrortu, p. 132.

Freud, S. (1991). Tótem y tabú. Obras Completas, Tomo XIII Buenos Aires, Argentina: Ed. Amorrortu.

Freud, S. (1991). Tres ensayos de teoría sexual. Obras Completas, Tomo VII Buenos Aires, Argentina: Ed. Amorrortu, pp. 113, 175 y 211.

Lacan, J. (1986). La ética del psicoanálisis [L'éthique de la psychanalyse]. París, Francia: Ed. Seuil, p. 142.

Lacan, J. (2005). Libro XXIII: El sinthoma: 1975-1976 [Livre XXIII: Le sinthome: 1975-1976]. París, Francia: Ed. du Seuil, p. 125.

Laplanche, J. y Pontalis J. (2004). Diccionario de psicoanálisis. Buenos Aires, Argentina: Ed. Paidós, pp. 181, 328 y 430.

Merton, R. (1979). La estructura precaria: orden y conflicto en la sociedad moderna. Ciudad de México: Ed. Edicol.

Nietzsche, F. (1990). Généalogie de la morale [Genealogía de la moral]. París, Francia: Librairie Générale Française, p. 118.

Stoller, R. (1984). La perversion et le désir de faire mal [ $\mathrm{La}$ perversión y el deseo de hacer daño]. Nouvelle revue de psychanalyse $\mathrm{N}^{\circ} 29$, p. 198.

Terestchenko, M. (2006). De l'utilité de la torture [De la utilidad de la tortura]. Revue du MAUSS No 28, pp. 337-366.

Winnicott, D. (2020). Las raíces de la agresión http://www. psicoanalisis.org/winnicott/ragres.htm 


\section{NOTAS}

1 La discusión respecto del lugar que ocupa la pulsión de apoderamiento (Bernächtigungstrieb) en la construcción de la teoría psicoanalítica freudiana es divergente. Autores como René Major, Jacques Sédat, André Green y otros, sitúan esta pulsión como la base de la perversión y de una crueldad originaria. Como lo indica Laplanche y Pontalis en su Diccionario de Psicoanálisis, el término, utilizado ocasionalmente por Freud, no puede codificarse con precisión (Laplanche y Pontalis, 2004). Nuestra posición es que la constitución de la pulsión de muerte permite esclarecer la obscuridad del término, definiendo la génesis del sadismo y de la crueldad como una derivación hacia el objeto de la pulsión de muerte, que originariamente busca destruir al propio sujeto. Es la razón por la que no pondremos el acento en este concepto a pesar de la importancia dada por algunos psicoanalistas al respecto. 2 Las películas de terror son un ejemplo de este juego de fascinación. Si a nivel superficial de interpretación se dice que la identificación del espectador está siempre del lado de la víctima, esto que Freud nos enseña es que la identificación es siempre doble. El espectador es el verdugo sádico, y a la vez, en una identificación masoquista, la víctima flagelada. Este placer/deseo obtenido por la puesta en escena de la crueldad, es filtrada moralmente en la estructura del film de horror por un clímax donde el "monstruo" recibe su castigo, que debe ser proporcional a la culpa que engendra el fantasma.

3 Existe una discusión, o más bien una toma de posición, acerca de la relación entre la pulsión de destrucción y la pulsión de agresión. Una posibilidad es diferenciar las dos pulsiones, la primera como dirigida hacia el aniquilamiento del objeto y la segunda hacia la dominación de este. Otra posibilidad es ver la pulsión de agresión como la manera por la cual se manifiesta en la humanidad la pulsión de destrucción, así como esta última es la manifestación más general de la pulsión de muerte. La tercera postura, que nosotros utilizaremos en nuestra investigación, es que, a partir del conjunto de la obra freudiana, no es posible deducir una diferenciación entre las dos pulsiones, pudiendo ambas utilizarse como expresión de la pulsión de muerte hacia el exterior. 